\title{
Correction to: Aquatic geochemistry of a major freshwater lake in the Kashmir Himalaya: solute acquisition and denudation process in the lacustrine system
}

\author{
Rouf Ahmad Shah · Javid Ahmad Ganaie · Sayar Yaseen • \\ Jairam Singh Yadav • Santosh Kumar Rai · Tanveer Ahmad Dar • \\ Sameer Kumar Tiwari
}

Published online: 14 January 2022

(C) Springer Nature Switzerland AG 2022

Correction to: Environ Monit Assess (2021) 193: 835

https://doi.org/10.1007/s10661-021-09623-9

The original version of this article unfortunately contained an error in Fig. 1.

The corrected Fig. 1 is shown below.

The original article can be found online at https://doi.org/ 10.1007/s10661-021-09623-9.

R. A. Shah $(\bowtie) \cdot$ J. S. Yadav · S. K. Rai · S. K. Tiwari

Wadia Institute of Himalayan Geology, Dehradun,

Uttarakhand 248001, India

e-mail: rouf@wihg.res.in

J. A. Ganaie ( $\square)$

Department of Earth Sciences, University of Kashmir,

Srinagar J\&K 190006, India

e-mail: jganai.ganai9@gmail.com

S. Yaseen

Department of Environmental Sciences, Govt. Degree

College Shopian, Shopian J\&K 192303, India

T. A. Dar

Department of Earth Sciences, Indian Institute

of Technology, Roorkee, Uttarakhand 247667, India 


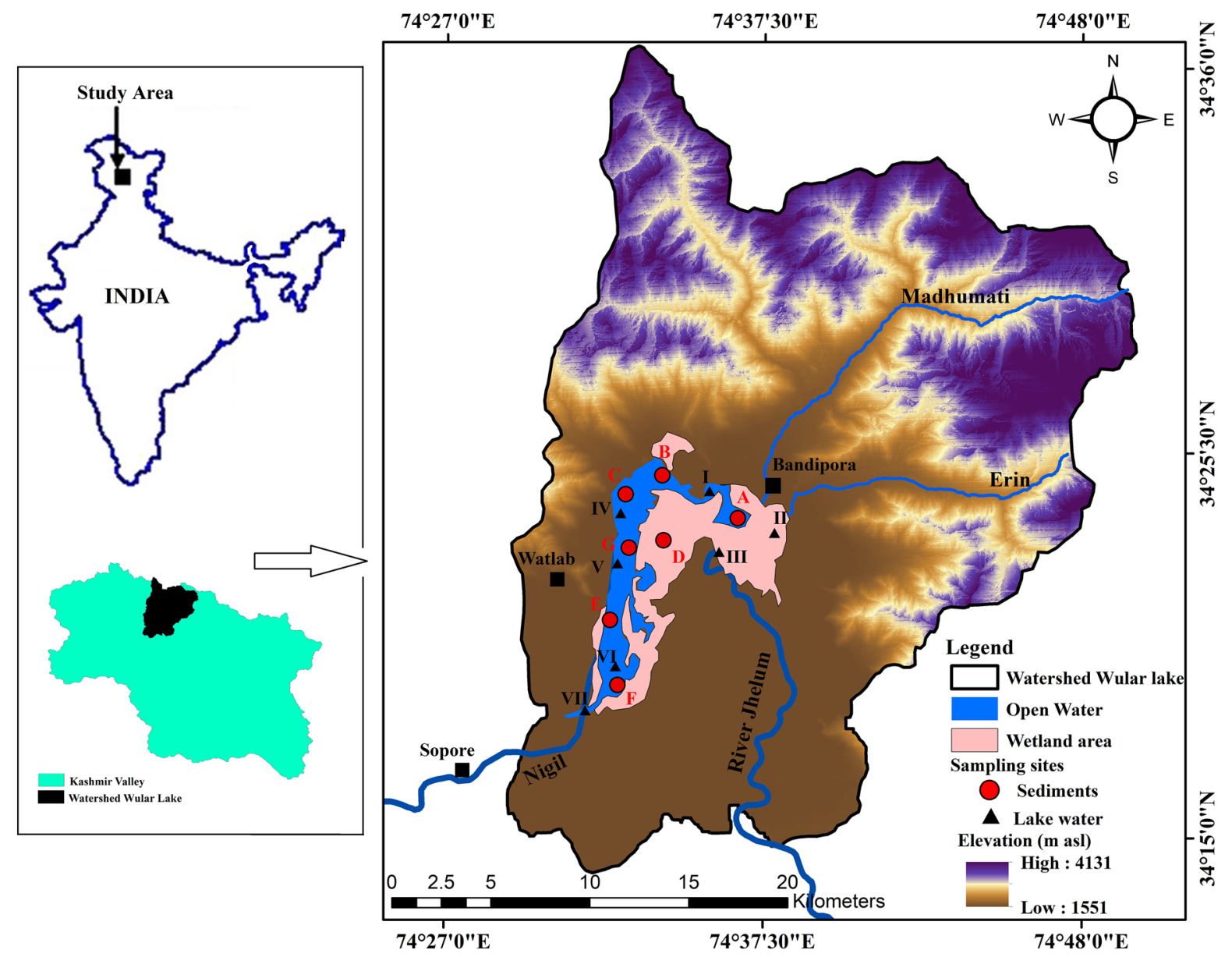

Fig. 1 Location of Wular Lake catchment showing the lake water and sediment sampling sites

Publisher's Note Springer Nature remains neutral with regard to jurisdictional claims in published maps and institutional affiliations. 